\title{
Chemotherapy or Allogeneic Stem Cell Transplantation as Salvage Therapy for Patients with Refractory Acute Myeloid Leukemia: A Multicenter Analysis
}

\author{
Zhong-yu Wang ${ }^{a}$ Wen-hui Gao a, bui-jin Zhao ${ }^{a}$ Chun-rong Yin ${ }^{c}$ \\ Zi-wei Wang ${ }^{d}$ Liang Tian ${ }^{\mathrm{e}}$ Ling Wang $^{\text {a }}$ Li-ning Wang ${ }^{\mathrm{a}}$ Jie-ling Jiang ${ }^{\mathrm{a}}$ \\ Raynier Devillier ${ }^{f}$ Ming Wan $^{e}$ Jian-Ming Wang ${ }^{d}$ Ping-ping Huang ${ }^{b}$ \\ Didier Blaise ${ }^{f}$ Jiong $\mathrm{Hu}^{\text {a }}$

\begin{abstract}
aShanghai Institute of Hematology, Blood and Marrow Transplantation Center, Department of Hematology, Collaborative Innovation Center of Hematology, Rui Jin Hospital, Shanghai Jiao Tong University School of Medicine, Shanghai, China; bepartment of Hematology, Institute of Hematology \& Blood Diseases Hospital, Chinese Academy of Medical Sciences \& Peking Union Medical College, Tianjin, China; 'Department of Hematology, Tong Ren Hospital, Shanghai Jiao Tong University School of Medicine, Shanghai, China; ${ }^{\mathrm{d} D e p a r t m e n t}$ of Hematology,

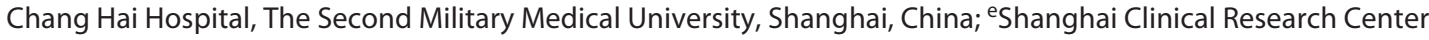
(SCRC), Feng Lin International Centre, Shanghai, China; ' Department of Hematology, Program of Transplantation and Cell Therapy, Program of Leukemia, Centre de recherche en Cancérologie de Marseille (CRCM), Institut Paoli-
\end{abstract} \\ Calmettes, Aix Marseille University, Marseille, France
}

\section{Keywords}

Acute myeloid leukemia · Allogeneic stem cell transplantation · Refractory · Salvage chemotherapy

\begin{abstract}
Introduction: The overall outcome of patients with refractory AML ( $r A M L)$ remains poor. Though allogeneic hematopoietic stem cell transplantation (allo-HSCT) is considered as the only curative therapy, it is routinely recommended only for patients after remission with salvage chemotherapy. Objective: In this study, we evaluated the impact of salvage chemotherapy or allo-HSCT on the overall outcome in $\mathrm{AML}$. Methods: We collected the clinical data of 220 patients from 4 medical centers and performed retrospective analysis of prognosis factors, including salvage chemotherapy, inten-
\end{abstract}

Karger@karger.com www.karger.com/aha

Karger $\stackrel{\text { ' }}{5}$

GOPEN ACCESS
(C) 2022 The Author(s)

Published by S. Karger AG, Basel

This is an Open Access article licensed under the Creative Commons Attribution-NonCommercial-4.0 International License (CC BY-NC) (http://www.karger.com/Services/OpenAccessLicense), applicable to the online version of the article only. Usage and distribution for commercial purposes requires written permission. sity of chemotherapy, and allo-HSCT. Results: A total of 29 patients received allo-HSCT directly without salvage chemotherapy, 26 patients achieved complete remission (CR) or complete remission with incomplete hematological recovery (CRi) after transplantation and 4-year leukemia-free survival (LFS) and overall survival (OS) were $45.0 \pm 10.7$ and 51.0 $\pm 10.6 \%$, respectively. Another 191 patients received salvage chemotherapy and 81 (42.2\%) achieved CR or CRi. Thirtyfour patients among them underwent subsequent allo-HSCT with 4-year LFS and OS of $46.0 \pm 8.8$ and $46.2 \pm 9.0 \%$. The 4-year LFS and OS in 26 patients who failed to obtain CR or CRi but received allo-HSCT with active disease were $32.9 \pm$

Zhong-yu Wang, Wen-hui Gao, and Hui-jin Zhao contributed equally to the manuscript.
Correspondence to:

Jian-Ming Wang, jmwangch@139.com 
10.0 and $36.9 \pm 10.8 \%$, respectively. For patients who received salvage chemotherapy but not allo-HSCT, few of them became long-term survivors. In multivariate analysis, salvage chemotherapy and the intensity of chemotherapy failed to have significant impact on both OS and LFS. AlloHSCT was the only prognostic factor for improved OS and LFS in multivariate analysis. Conclusions: These results indicate the benefit of allo-HSCT in patients with rAML and direct allo-HSCT without salvage chemotherapy could be treatment option.

(c) 2022 The Author(s)

Published by S. Karger AG, Basel

\section{Introduction}

Patients with refractory AML (rAML) usually respond poorly to conventional chemotherapy and present with dismal outcomes [1-5]. Treatment options in the setting of refractory disease are limited [1]. Though there is no acceptable standard regimen as salvage chemotherapy, different trials with intensive salvage chemotherapy, such as dose escalation of daunorubicin within the " $7+3$ " regimen [6-8], multiple combination of etoposide, cytarabine with mitoxantrone or idarubicin (MAC or ICE) $[9,10]$, or high-dose cytarabine (HiAC) containing regimen with fludarabine, cladribine with or without idarubicin, or mitoxantrone [11, $12]$, lead to the complete remission (CR) rates of 20 $40 \%$, and few patients became long-term survivor. More recently, the clinical trials to add new agents such as gemtuzumab ozogamicin, all-trans retinoic acid, and molecular target agents, including FLT3 inhibitor as adjunct to intensive chemotherapy may increase the overall response rate, but still these trials offer almost no chance of cure [12-16].

Allogeneic hematopoietic stem cell transplantation (allo-HSCT) is considered as the only curative therapy for rAML [17]. Several reports suggest that immediate transplantation without salvage therapy is feasible for AML patients with primary induction failure (PIF) or at first relapse, if an available donor can be quickly identified [18, 19]. However, other reports show that achieving remission, through salvage chemotherapy, can lead to favorable outcomes and better survival suggesting that achieving remission may indicate intrinsically more responsive leukemia [20,21]. Since allo-HSCT in rAML is associated with relative high non-relapse mortality and relapse rate, it is not regularly recommended in patients with rAML but mostly for patients achieved remission with salvage therapy.

\section{Materials and Methods}

This retrospective analysis included patients with rAML receiving treatment between January 2008 to December 2017 from 4 different medical centers. The inclusion criteria were as following: (1) patients fulfilled one of the criteria of refractory AML, which including PIF after 2 or more cycles of chemotherapy, first early relapse after a remission duration of fewer than 6 months, late first relapse after a remission duration of 6-12 months and refractory to salvage chemotherapy, or multiple relapses; (2) age from 16 to 64 ; (3) the diagnostics and treatment at primary diagnosis of AML were performed at each center; (4) treatment outcome and subsequent follow-up data can be documented from patients charts or outpatients records. The risk stratification was based on the European LeukemiaNet 2017 recommendations with cytogenetic and molecular analysis outcome [22]. The study procedure including the collection and analysis of patients' data were in accordance with the Helsinki Declaration. Written consent was obtained from patients for data use in clinical research. All patients gave informed consent and the institutional review board of participating centers approved allogeneic transplantation protocols and/or salvage chemotherapy regimens.

\section{Treatment}

A total of 220 patients were included in the final analysis with median age of 42 (16-64). The salvage therapy included intensified chemotherapy $(n=81,36.8 \%)$, non-intensive chemotherapy $(n=$ $110,50 \%)$ and direct allogeneic HCT without salvage chemotherapy $(n=29,13.2 \%)$. The intensified chemotherapy included HiAC (3 g/m² b.i.d., days 1-3), FLAG-based regimens (FLAG or FLAGIDA with cytarabine $2 \mathrm{~g} / \mathrm{m}^{2}$ for 5 days, FLAG-Mito with cytarabine $1 \mathrm{~g} / \mathrm{m}^{2}$ b.i.d. days $1-5$ ), and CHA regimen (cytarabine $2 \mathrm{~g} / \mathrm{m}^{2}$ together with cladribine $10 \mathrm{mg}$ and homoharringtonine $4 \mathrm{mg}$ from day 1-5). Non-intensified chemotherapy, including MAC regimen (mitoxantrone $8-10 \mathrm{mg} / \mathrm{m}^{2}$, day $1-3$ with cytarabine $100 \mathrm{mg} / \mathrm{m}^{2}$ day 1-7 and cyclophosphamide $400 \mathrm{mg} / \mathrm{m}^{2}$, day 2 and day 5) or CAG regimen (aclacinomycin $20 \mathrm{mg}$ day 1-4 with Ara-C $15 \mathrm{mg}$ / $\mathrm{m}^{2}$, bid, day $1-14$ and G-CSF $5 \mu \mathrm{g} / \mathrm{kg}$, day $\left.1-14\right)$. Among these 191 patients, 60 patients underwent allo-HSCT (34 in remission and 26 in active disease) after salvage chemotherapy. No patients received non-myeloablative conditioning regimens. The common conditioning regimens used were standard myeloablative regimen (MAC) with busulfan and cyclophosphamide (Bu-Cy), fludarabine, cytarabine, and busulfan (Flu-Bu-Ara-C) and an intensified conditioning with sequential cytoreductive chemotherapy with fludarabine, cytarabine, and idarubicin (FLAG-IDA) followed by a reduced toxicity conditioning with fludarabine and 3-day busulfan (Flu-Bu3) at the hematological nadir of chemotherapy-induced aplasia. After allo-HSCT, the early tapering and/or stop of immunosuppression and prophylactic donor lymphocyte infusion were carried out based on the protocols of participating centers.

\section{Response Criteria and Survival End Point}

The response criteria were established according to revised recommendations of the International Working Group for Diagnosis, Standardization of Response Criteria, Treatment Outcomes and Reporting Standards for Therapeutic Trials in Acute Myeloid Leukemia [23]. CR was defined as $<5 \%$ blasts in the bone marrow with normal peripheral and differential counts (granulocytes $>1,000$ / $\mathrm{mm}^{3}$ and platelets $>100,000 / \mathrm{mm}^{3}$ ) without extramedullary dis- 
ease. CR with incomplete hematological recovery (CRi) was defined as $<5 \%$ blasts in the bone marrow with peripheral platelet counts below $100,000 / \mathrm{mm}^{3}$. Partial response was established as either 5-20\% BM blasts, a $\geq 50 \%$ decrease in BM blasts or $<5 \%$ BM blasts but with the presence of Auer rod. No remission was established for patients who did not fulfill the above criteria. Overall survival (OS) was calculated from the date of refractoriness until death or last follow-up. Leukemia-free survival (LFS) was calculated from the date of CR/CRi until relapse or last disease-free follow-up. Cytogenetics abnormalities were classified according to the SWOG/ECOG criteria.

\section{Statistical Analysis}

The pairwise comparison between patient subgroups was performed via the Mann-Whitney analysis. The Kruskal-Wallis test and Fisher's exact test were used to compare the continuous variables or categorical variables between different groups. Distributions of OS and LFS were estimated by the Kaplan-Meier method and differences in OS according to risk factors were analyzed by the log-rank test. In addition, univariate and multivariate Cox regression analyses were performed to evaluate the effects of relevant covariates on OS and LFS. For multivariate analysis, only factors with $p$ value of $<0.1$ in the univariate analysis were included. Ninety-five percent confidence interval for risk ratio (RR) were obtained. For all analyses, a $p$ value was considered statistically significant if it was $\leq 0.05$. All statistical analyses were performed with SPSS software (version 19).

\section{Results}

\section{Patients' Characteristics}

A total of 220 patients were included in the final analysis. According to the disease status, 96 (43.6\%) patients had PIF, 57 (25.9\%) were in their first relapse with the first CR $<6$ months, 61 (27.7\%) in the first relapse with CR1 for $>6$ months but refractory to re-induction chemotherapy, and $6(2.7 \%)$ patients experienced the second and subsequent relapses. Among 220 patients, 29 patients underwent allo-HSCT directly without any salvage chemotherapy, while 191 patients underwent salvage chemotherapy. In the group of directly allo-HSCT without salvage chemotherapy, more patients were $\geq 40$ years, with PIF disease and a lower percentage of blast in bone marrow compared to those patients who recieved salvage chemotherapy, as shown in Table 1 . The cytogenetic and molecular profile data were available for only $166 \mathrm{pa}-$ tients. Most frequent mutations were FLT3-ITD $(n=21$, including 4 with NPM1 mutation) or FLT3 TKD mutation $(n=1)$, followed by KMT2A rearrangement $(n=9)$ and C-kit mutation ( $n=7$, including 5 with RUNX1RUNX1T1 and 1 with CBFB-MYH11). The risk stratification and other characteristics of patients are summarized in Table 1.

Allogeneic Stem Cell Transplantation for

Patients with Refractory AML
Table 1. Patients' characteristics of all patients

\begin{tabular}{|c|c|c|}
\hline & \multicolumn{2}{|l|}{ Patients, $n$ (\%) } \\
\hline & $\begin{array}{l}\text { without salvage } \\
\text { chemo }(n=29)\end{array}$ & $\begin{array}{l}\text { salvage chemo } \\
(n=191)\end{array}$ \\
\hline \multicolumn{3}{|l|}{ Age, years, $n(\%)$} \\
\hline$<40$ & $7(24.1)$ & $99(51.8)^{*}$ \\
\hline$\geq 40$ & $22(75.9)$ & $92(48.2)$ \\
\hline Male, $n(\%)$ & $10(34.5)$ & $106(56.0)^{\#}$ \\
\hline \multicolumn{3}{|l|}{ WBC, $10^{9} / \mathrm{L}$} \\
\hline Median (range) & $49(1.84-78.7)$ & $12.78(0.43-265)$ \\
\hline \multicolumn{3}{|l|}{ Hemoglobin, g/dL } \\
\hline Median (range) & $78(43-118)$ & $84(32-194)$ \\
\hline \multicolumn{3}{|l|}{ Platelet, $10^{9} / \mathrm{L}$} \\
\hline Median (range) & $73(12-183)$ & $50(3-295)$ \\
\hline \multicolumn{3}{|l|}{ Bone marrow blasts, $\%$} \\
\hline Median (range) & $39(4-91)$ & $61(8.9-95)^{*}$ \\
\hline \multicolumn{3}{|l|}{ Stage, $n(\%)$} \\
\hline PIF & $15(51.7)$ & $81(42.4)^{\#}$ \\
\hline 1st rel: CR1 <6 months & $14(48.3)$ & $43(22.5)$ \\
\hline 1st rel: CR1 $\geq 6$ months & $0(0)$ & $61(31.9)$ \\
\hline 2nd rel or beyond & $0(0)$ & $6(3.1)$ \\
\hline \multicolumn{3}{|l|}{ Cytogenetics, $n(\%)$} \\
\hline Favorable & $0(0)$ & $30(15.7)$ \\
\hline Intermediate & $11(37.9)$ & $70(36.6)$ \\
\hline Adverse & $14(48.3)$ & $41(21.5)$ \\
\hline Not available & $4(13.8)$ & $50(26.2)$ \\
\hline Allo-HSCT, $n(\%)$ & $29(100)$ & $60(31.4)^{*}$ \\
\hline
\end{tabular}

PIF, primary induction failure; allo-HSCT, allogeneic hematopoietic stem cell transplantation. ${ }^{\#} p \leq 0.05 .{ }^{*} p \leq 0.01$.

Patients who received salvage chemotherapy were further divided according to the intensity of therapy. A total of 81 patients received chemotherapy with $\mathrm{HiAC}$ and 110 patients received salvage therapy without HiAC. Overall, there was no significant difference in regard to white blood count, hemoglobin, platelets, bone marrow blasts, and cytogenetic/molecular profiles as shown in online suppl. Table 1 (for all online suppl. material, see www. karger.com/doi/10.1159/000511144).

\section{Response to Therapy and Overall Outcome}

For those patients receiving salvage chemotherapy, 81 (42.4\%) achieved CR or CRi, 19 (9.9\%) obtained only partial remission, and 91 (47.6\%) with no response. In those patients who directly underwent allo-HSCT without salvage chemotherapy, 26 out of 29 (89.7\%) achieved CR/ $\mathrm{CRi}$, which was significantly higher than the salvage chemotherapy group $(p<0.001)$.

At the last follow-up with a median follow-up of 24.4 months, a total of 72 patients remained alive with an over- 


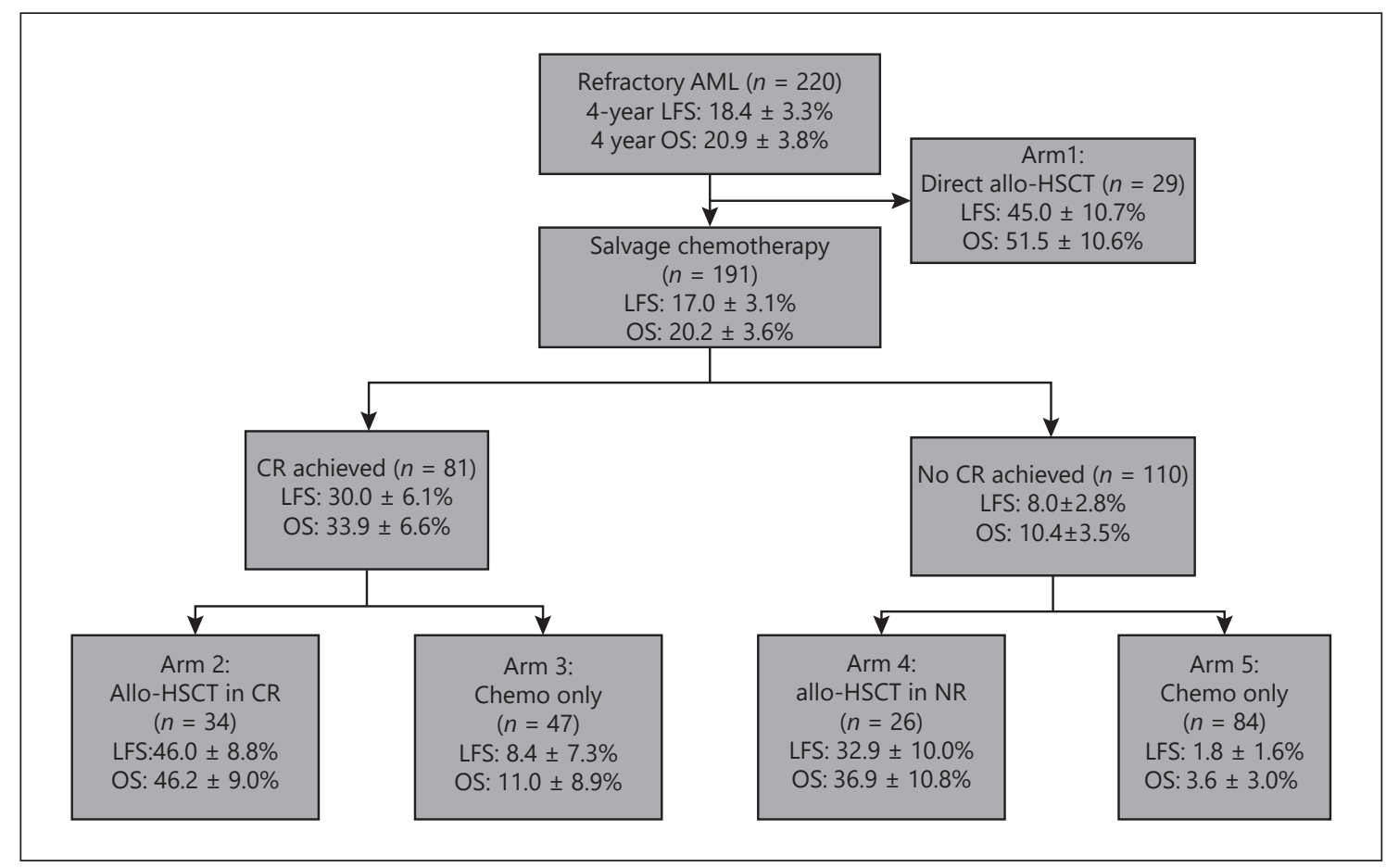

Fig. 1. Patients' flow chart and outcome according to the treatment group. LFS, leukemia-free survival; OS, overall survival; all-HSCT, allogeneic hematopoietic stem cell transplantation; CR, complete remission.

all median OS of 10.0 months, while only 56 patients remain alive in CR/CRi with a median LFS of 8.9 months. The 4-year estimated OS and LFS were $20.9 \pm 3.8$ and 18.4 $\pm 3.3 \%$, respectively, as shown in Figure 1 .

\section{Overall Outcome Analysis Based on Allo-HSCT}

According to the treatment received, we identified several groups of patients. For patients directly undergoing allo-HSCT, the estimated 4-year OS and LFS were $51.5 \pm 10.6$ and $45.0 \pm 10.7 \%$, respectively. For 81 patients who obtained CR/CRi after salvage chemotherapy, 38 (46.9\%) received subsequent allo-HSCT and 47 failed to undergo alloHSCT. The 4-year OS/LFS for these 2 groups were $46.2 \pm$ $9.0 / 46.0 \pm 8.8$ and $11.0 \pm 8.9 \% / 8.4 \pm 7.3 \%$, respectively. Among 110 patients who failed to obtain CR/CRi after salvage chemotherapy, only 26 eventually underwent rescuing allo-HSCT with active disease. The 4-year OS and LFS were $36.9 \pm 10.8$ and $32.9 \pm 10.0 \%$ for patients in the allo-HSCT group with only $3.6 \pm 3.0$ and $1.8 \pm 1.6 \%$ in 84 patients who did not receive allo-HSCT (as shown in Fig. 1).

\section{Prognostic Factors via Univariate/Multivariate \\ Analysis}

In univariate analysis, we analyzed the impact of intensity of salvage chemotherapy on the treatment outcome.
Of the 81 intensively treated patients, the 4-year LFS and OS were $21.1 \pm 9.6 \%$ (median 2.8 months) and $23.2 \pm$ $5.1 \%$ (median 8.8 months), respectively. For patients treated with non-intensive chemotherapy, the 4-year LFS and OS were $9.6 \pm 4.0 \%$ (median 2.1 months) and $14.4 \pm$ $4.8 \%$ (median 9.4 months) as shown in Figure 2. The $p$ values were 0.68 and 0.72 for OS and LFS, respectively. Of interest, patients treated with allo-HSCT directly without salvage chemotherapy had significantly improved OS and LFS (as shown in Figure 2 and Table 2). Secondary, we evaluated the impact of allo-HSCT on the overall outcome. The 4-year OS of the HSCT group (including direct allo-HSCT) was overwhelmingly better than patients who did not receive HSCT group ( $43.8 \pm 6.1$ vs. $8.0 \pm$ $3.6 \%, p<0.001$, as shown in Fig. 3). Besides these 2 factors, younger patients ( $<40$ vs. $\geq 40$, as shown in Fig. 4 ) tended to have improved OS. All other factors such as risk stratification by cytogenetic/molecular profiling and disease stage were not associated with OS (as shown in Table 2). Using a Cox regression model for multivariate analysis, patients receiving allo-HSCT was the only factor associated with a better $\mathrm{OS}(\mathrm{RR}=2.38, p<0.001$, as shown in Table 3).

As to the LFS, in univariate analysis, younger age and direct allo-HSCT without salvage chemotherapy and re- 
Fig. 2. Kaplan-Meier curves of OS and LFS in patients who received intensive salvage chemotherapy, non-intensive salvage chemotherapy, and direct allo-HSCT without allo-HSCT. LFS, leukemia-free survival; OS, overall survival; all-HSCT, allogeneic hematopoietic stem cell transplantation.

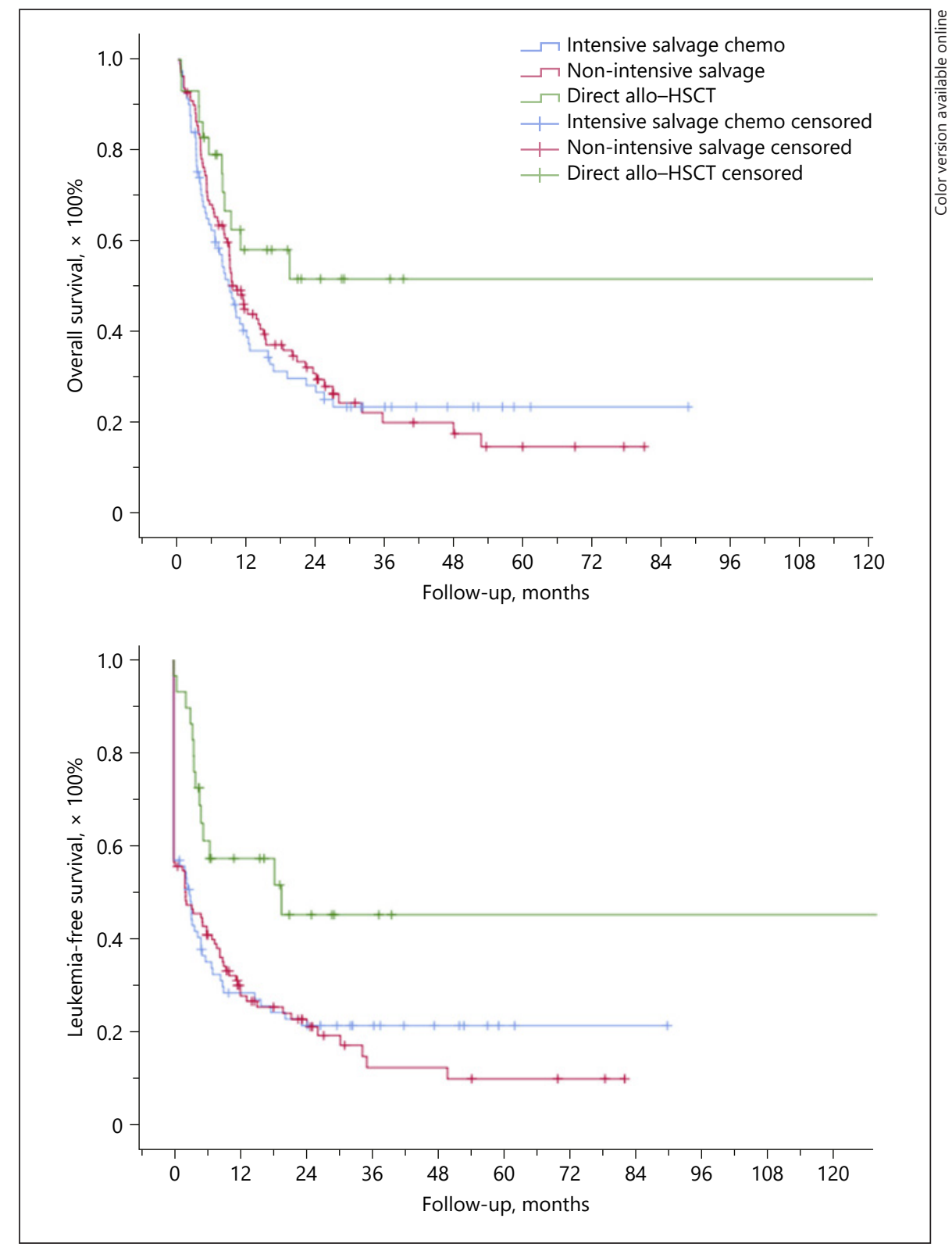

ceiving allo-HSCT at any time were associated with improved LFS (Table 2 ). In multivariate analysis, the only factor significantly associated with improved LFS was allo-HSCT $(\mathrm{RR}=2.83, p<0.001$, Table 3$)$.

\section{Impact of Timing of Allo-HSCT, Disease Status, and Conditioning Regimens in Patients Undergoing Allo- HSCT}

In our series, a total of 89 patients underwent allo-HSCT directly without chemotherapy $(n=29)$ or after salvage chemotherapy either in remission $(n=34)$ or with active disease $(n=26)$. The 4 -year OS and LFS were both around $45 \%$ for patients underwent allo-HSCT up-front or in CR after salvage chemotherapy. For those patients who underwent alloHSCT with active disease after salvage chemotherapy, the OS and LFS decreased to 36.9 and $32.9 \%$, respectively, but not significant different from the previous groups perhaps due to limited statistical power as shown in Table 4. For patients with primary refractory disease, the OS and LFS were similar to all other patients with relapsed disease after first remission. As to the conditioning regimens, 50 patients received standard regimens and 39 patients received sequential conditioning regimens. The OS and LFS were similar between the 2 sets of conditioning as shown in Table 4 . 
Table 2. Univariate analysis of patients and treatment-related factors associated with OS and LFS

\begin{tabular}{|c|c|c|c|c|}
\hline Parameters & 4-year OS, \% & $p$ value & 4-year LFS, \% & $p$ value \\
\hline \multicolumn{5}{|l|}{ Age } \\
\hline$<40$ years & $30.2 \pm 5.5$ & \multirow{2}{*}{0.071} & $27.7 \pm 4.8$ & \multirow{2}{*}{0.015} \\
\hline$\geq 40$ years & $19.1 \pm 4.6$ & & $8.2 \pm 4.3$ & \\
\hline \multicolumn{5}{|l|}{ BM blasts at diagnosis, $\%$} \\
\hline$<50$ & $28.2 \pm 4.6$ & \multirow[b]{2}{*}{0.503} & $23.2 \pm 4.6$ & \multirow[b]{2}{*}{0.300} \\
\hline$\geq 50$ & $19.0 \pm 4.9$ & & $17.1 \pm 4.3$ & \\
\hline \multicolumn{5}{|l|}{ Salvage chemotherapy $(\mathrm{Y} / \mathrm{N})$} \\
\hline Yes & $20.2 \pm 3.6$ & \multirow{2}{*}{0.03} & $17.0 \pm 3.1$ & \multirow{2}{*}{0.003} \\
\hline No & $51.5 \pm 10.6$ & & $45.0 \pm 10.7$ & \\
\hline \multicolumn{5}{|l|}{ Salvage chemo intensity } \\
\hline Intensive salvage chemo & $23.2 \pm 5.1$ & \multirow{2}{*}{0.68} & $21.1 \pm 9.6$ & \multirow{2}{*}{0.72} \\
\hline Non-intensive salvage chemo & $14.4 \pm 4.8$ & & $9.6 \pm 4.0$ & \\
\hline \multicolumn{5}{|l|}{ Cyto/mol $(n=166)$} \\
\hline Favorable $(n=30)$ & $24.2 \pm 9.4$ & \multirow{3}{*}{0.513} & $20.8 \pm 7.8$ & \multirow{3}{*}{0.455} \\
\hline Intermediate $(n=81)$ & $16.7 \pm 7.8$ & & $9.1 \pm 6.9$ & \\
\hline Adverse $(n=55)$ & $20.0 \pm 6.5$ & & $18.9 \pm 5.9$ & \\
\hline \multicolumn{5}{|l|}{ Stage } \\
\hline PIF & $33.4 \pm 6.1$ & \multirow{4}{*}{0.238} & $31.2 \pm 5.4$ & \multirow{4}{*}{0.137} \\
\hline 1st rel: CR1 <6 months & $31.2 \pm 6.8$ & & $30.9 \pm 6.7$ & \\
\hline 1 st rel: $C R 1 \geq 6$ months & $11.2 \pm 4.9$ & & $7.0 \pm 4.5$ & \\
\hline 2nd rel or beyond & 0 & & 0 & \\
\hline \multicolumn{5}{|l|}{ Allo-HSCT (Y/N) } \\
\hline Yes & $8.0 \pm 3.6$ & \multirow[b]{2}{*}{$<0.001$} & $2.5 \pm 2.3$ & \multirow[b]{2}{*}{$<0.001$} \\
\hline No & $43.8 \pm 6.1$ & & $41.5 \pm 5.8$ & \\
\hline
\end{tabular}

PIF, primary induction failure; LFS, leukemia-free survival; OS, overall survival; all-HSCT, allogeneic hematopoietic stem cell transplantation. Values in italics indicate $p$ values $<0.1$.

\section{Discussion}

Refractory AML remains a clinical challenge. A limited proportion of patients may respond to salvage chemotherapy such as MAC or combination of HiAC with Fludarabine or cladribine, while the remission duration is usually short and most patients die of subsequent disease relapse [8-11]. Even though multiple clinical trials carried out with new therapeutic agents, the overall remission rates reported are low with few long-term survivors [12-16]. Allogeneic HSCT is considered as the only therapeutic option, and the retrospective analysis demonstrated that $\sim 70 \%$ patients can obtain clinical remission and 2- to 3-year OS and DFS may vary between 15 and $40 \%[24,25]$.

The timing of allo-HSCT is a key issue particularly the remission status at allo-HSCT may have profound impact on transplantation outcome. Multiple reports suggest that leukemia burden remains as the most important factors for patients with AML receiving allo-HSCT either in both remission and refractory status [26, 27]. For example, in patients with AML in CR1, the pre-transplantation
MRD was considered as key prognostic factor [26]. As to the patients with non-remission AML, the Japanese database analysis demonstrated that the percentage of bone marrow blasts ( $<20$ vs. $20 \sim 60$ vs. $\geq 60 \%$ ) with or without circulating blasts was associated with treatment outcome after allo-HSCT [28]. These data indicate that attempts to achieve a CR or successful leukemia debulking may benefit for rAML and allo-HSCT is not regularly recommended for patients unless they obtained remission after salvage chemotherapy.

Unfortunately, the response to salvage chemotherapy for rAML is limited in the clinical settings. Clinical reports indicate that salvage chemotherapy may benefit only patients with long CR1 duration (>18 months) and/ or with favorable cytogenetics while patients with short CR1, high-risk cytogenetics, or FLT3-ITD usually had a low response rate [29-31]. For patients not responding to salvage therapy, the accumulated toxicity and infections complications may have negative impact on the subsequent allo-HSCT.

In this multicenter analysis in relative young adult patients with a median age of 40 years, we aim to evaluate 
Fig. 3. Kaplan-Meier curves of OS and LFS in patients underwent to allo-HSCT or not. LFS, leukemia-free survival; OS, overall survival; all-HSCT, allogeneic hematopoietic stem cell transplantation.
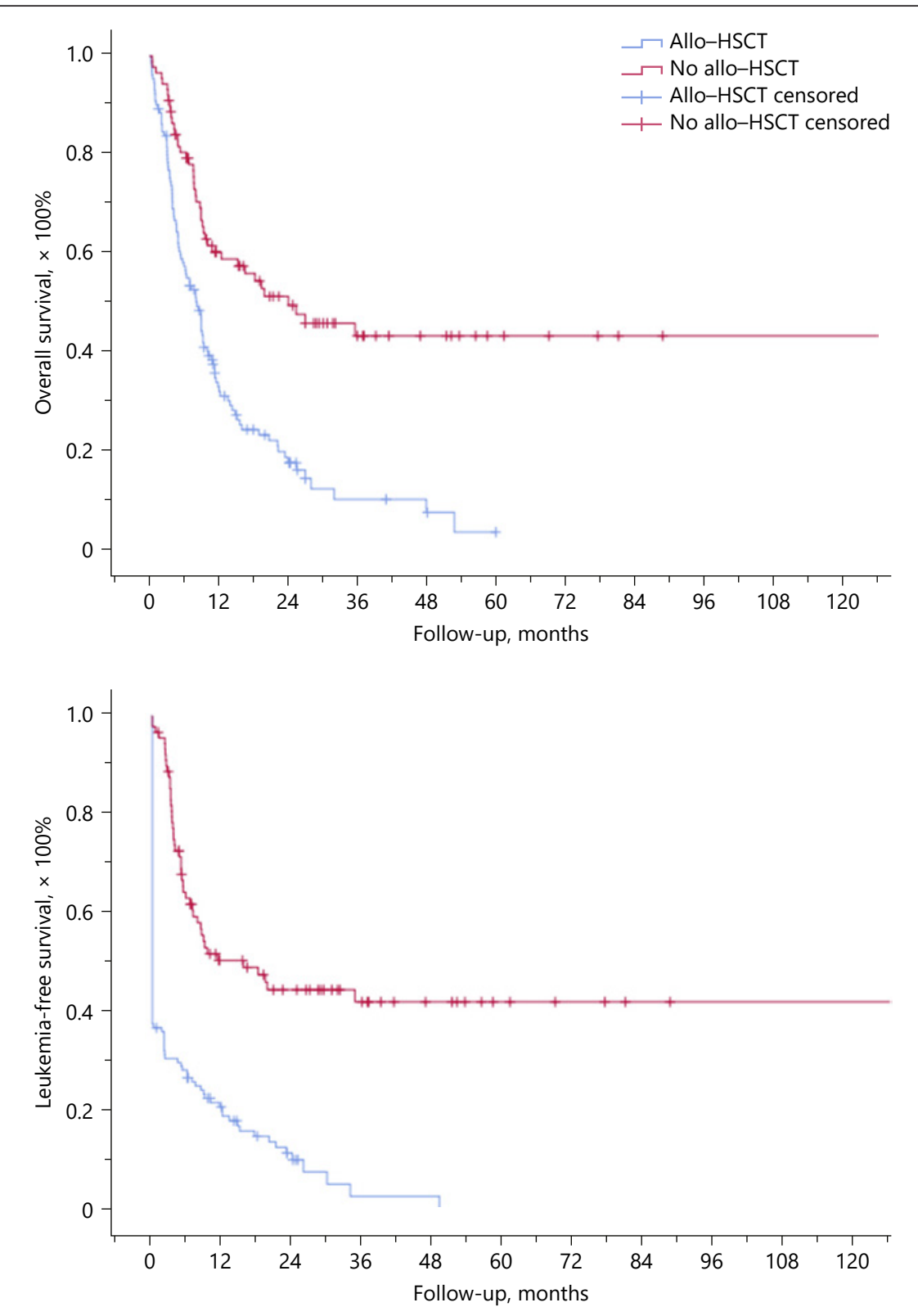

the impact of salvage chemotherapy and allo-HSCT on the overall outcome of patients with rAML. Several groups of patients were identified according to the treatment received: patients undergoing direct allo-HSCT without salvage chemotherapy, patients obtaining CR to salvage chemotherapy with or without subsequent alloHSCT, and patients not responding to salvage chemotherapy with or without subsequent allo-HSCT. Overall, our data demonstrated that direct allo-HSCT without salvage chemotherapy might be an option in rAML. The 4 -year OS and LFS were superior than patients under- went salvage chemotherapy overall and were also comparable for those patients received subsequent allo-HSCT after CR/CRi with salvage chemotherapy. To rule out the possible impact of difference of patients' characteristic, a propensity analysis was performed with 23 patients undergo direct allo-HSCT were paired with patients undergoing salvage chemotherapy with fuzz match for age, sex, risk stratification, and bone marrow blast (as shown in online suppl. Table 2). The analysis confirmed that direct transplantation was superior to patients undergo salvage chemotherapy. Secondary, we also analyzed the impact of 
Table 3. Multivariable analysis of prognostic factors associated with OS and LFS for all patients $(n=220)$
Fig. 4. Kaplan-Meier curves of OS and LFS in patients with age $<40$ versus $\geq 40$ years. LFS, leukemia-free survival; OS, overall survival; all-HSCT, allogeneic hematopoietic stem cell transplantation.

\begin{tabular}{|c|c|c|c|c|c|c|}
\hline \multirow[t]{2}{*}{ Parameters } & \multicolumn{3}{|l|}{ OS } & \multicolumn{3}{|l|}{ LFS } \\
\hline & $\mathrm{RR}$ & $95 \% \mathrm{Cl}$ & $p$ value & $\mathrm{RR}$ & $95 \% \mathrm{Cl}$ & $p$ value \\
\hline Age & 0.91 & $0.64-1.29$ & 0.59 & 0.86 & $0.61-1.19$ & 0.35 \\
\hline Salvage chemo & 1.08 & $0.54-2.19$ & 0.82 & 1.12 & $0.58-2.16$ & 0.73 \\
\hline Allo-HSCT & 2.38 & $1.53-3.68$ & $<0.001$ & 2.83 & $1.85-4.33$ & $<0.001$ \\
\hline
\end{tabular}

LFS, leukemia-free survival; OS, overall survival; $\mathrm{Cl}$, confidence interval; $\mathrm{RR}$, risk ratio; all-HSCT, allogeneic hematopoietic stem cell transplantation.Values in italics indicate $p$ values $<0.1$.

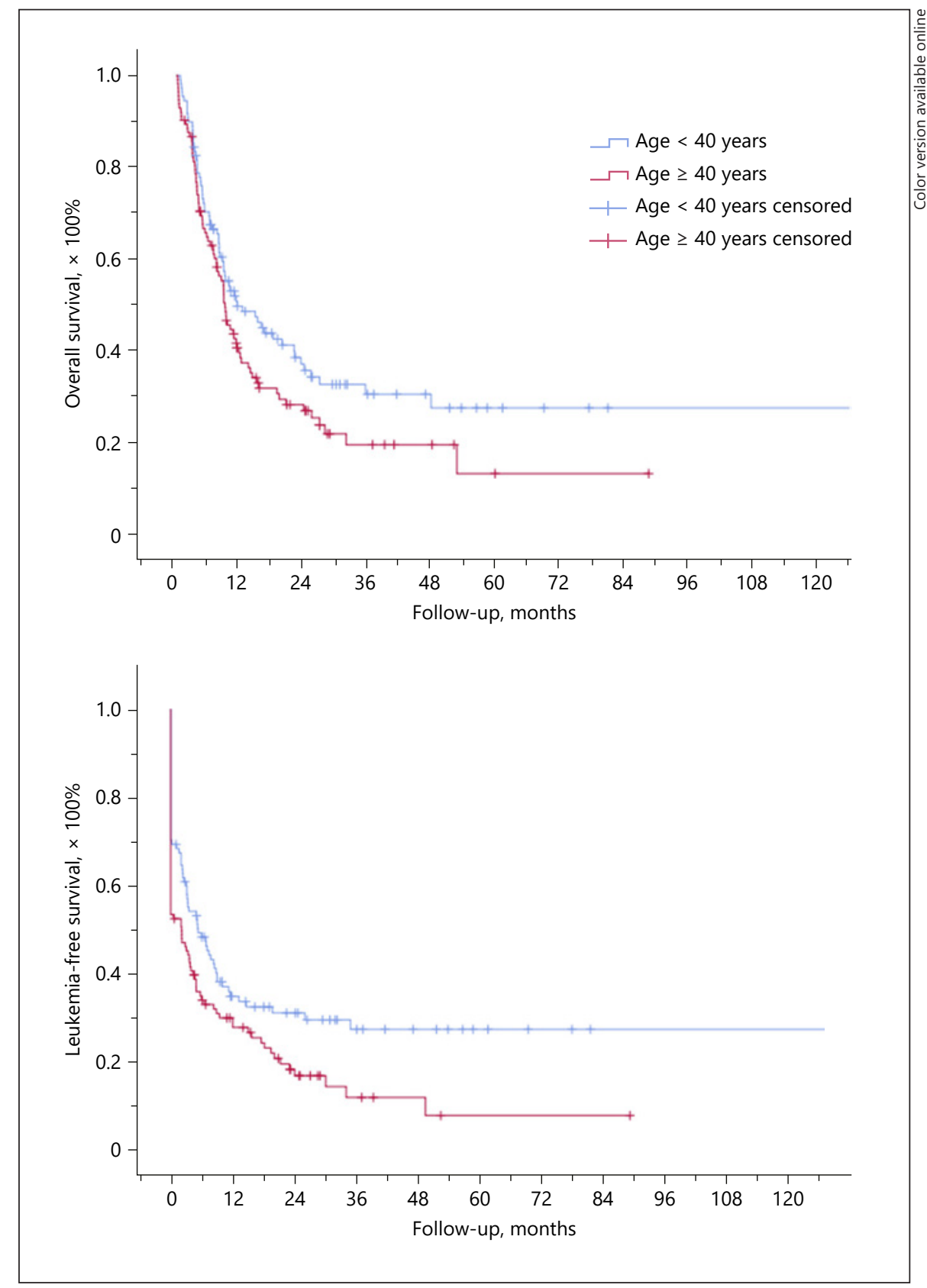


Table 4. Subgroup analysis of patients underwent allo-HSCT

\begin{tabular}{lllll}
\hline Parameters & 4-year OS, \% & $p$ value & 4-year LFS, \% & $p$ value \\
\hline $\begin{array}{llll}\text { Timing of allo-HSCT } \\
\quad \text { Up-front }\end{array}$ & & & & \\
$\quad$ CR after salvage chemo & $41.5 \pm 10.6$ & & $45.0 \pm 10.7$ & \\
$\quad$ No CR after salvage chemo & $36.2 \pm 9.0$ & $0.87^{*}$ & $46.0 \pm 8.8$ & $0.70^{*}$ \\
$\begin{array}{l}\text { Disease status } \\
\quad \text { PIF }(n=35)\end{array}$ & $46.3 \pm 9.0$ & & $32.9 \pm 10.0$ & $0.36^{\wedge}$ \\
$\quad$ All others $(n=54)$ & $39.3 \pm 8.1$ & 0.14 & $39.0 \pm 7.6$ & 0.18 \\
$\begin{array}{l}\text { Conditioning regimens } \\
\quad \text { Conventional regimen }\end{array}$ & $42.0 \pm 8.4$ & & $41.7 \pm 8.0$ & \\
$\quad$ Sequential regimen & $46.1 \pm 8.6$ & 0.58 & $42.7 \pm 8.7$ & 0.53 \\
\hline
\end{tabular}

CR, complete remission; PIF, primary induction failure; LFS, leukemia-free survival; OS, overall survival; all-HSCT, allogeneic hematopoietic stem cell transplantation. * Up-front versus $\mathrm{CR}$ after salvage chemo. ${ }^{\wedge}$ Up-front versus no $\mathrm{CR}$ after salvage chemo. intensity of chemotherapy on the overall outcome. In univariate analysis, there was no difference. Finally, in the multivariate analysis, only allo-HSCT remained as significant for improved OS and LFS, while salvage chemotherapy was not critical for the treatment outcome. Our data were in line with previous AMLSG study, which showed that only allo-HSCT was the key factor for the treatment of rAML [32].

Based on these data, we may speculate that allo-HSCT should be considered for patients with rAML if eligible and direct allo-HSCT without salvage chemotherapy can be treatment option especially for those patients with high-risk factors who are unlikely to respond to salvage chemotherapy. As in our previous study with sequential chemotherapy of FLAG-IDA followed by Flu-Bu conditioning regimen with an interval of 7 days in $\mathrm{rAML}$, we demonstrated that almost all patients had an extreme hypocellular bone marrow after FLAG-IDA. Therefore, the conditioning regimen was given at time of bone marrow with extreme low leukemia burden, which may mimic a transplantation given at remission or low MRD level [33]. The other rationale for up-front transplantation is related to the development or accumulation of resistance or refractoriness to chemotherapy and toxicities with multiple cycles of salvage chemotherapy, which may have an negative impact on the overall outcome of subsequent alloHSCT.

This strategy is also feasible for patients with primary refractory diseases. The OS and LFS were similar to patients with relapsed disease after initial remission (as shown in Table 4). Further analysis also showed that the outcome of direct allo-HSCT was as good as allo-HSCT after salvage chemotherapy for patients with PIF (data not shown). These findings may be in line with the early study, which showed that allo-HSCT with sequential FLAMSA regimen lead to a promising outcome in patients with refractory AML received only 2 cycles of chemotherapy [18].

As to the transplantation conditioning for rAML, standard conditioning to more intensified or sequential conditioning regimens have been reported with variables outcome $[18,33,34]$. In our series, there was no difference in OS and LFS between conditioning regimens as shown in Table 4, which may due to lack of statistical power, imbalanced distribution of patients' characteristics and preferred regimens used in different centers. For example, the sequential conditioning regimen for upfront allo-HSCT was exclusively used in Rui Jin Hospital and Paoli-Calmettes Cancer Center, while other participating centers relied on standard MAC conditioning with more aggressive posttransplantation procedures such as early tapering of immunosuppression and prophylactic donor lymphocyte infusion [34].

One possible bias of our study is lack of description or definition of aggressiveness of rAML. Though there was no difference in the WBC count in patients receiving direct allo-HSCT and salvage chemotherapy (Table 1), salvage chemotherapy usually should be given to patients with rapid increased of leukocytes or hyperleukocytosis in the clinical setting. Those patients with more "indolent" disease with stable WBC can undergo direct alloHSCT after work-up for transplantation. Other limitations of this study were obviously the retrospective nature, limited number of patients particularly in the group of direct allo-HSCT and lack of MRD data for analysis. Thus, no firm conclusion can be made based on potential 
selection bias. Even though with the limitation, we believed that prospective clinical study with minimal selection bias is warranted to evaluate the role of direct alloHSCT without salvage chemotherapy in young adult patients with rAML.

\section{Acknowledgements}

We acknowledge all the clinical staff of Rui Jin Hospital, Tong Ren Hospital, Chang Hai Hospital, Institut Paoli-Calmettes, and Institute of Hematology \& Blood Diseases Hospital, who helped with constant support and collaboration.

\section{Statement of Ethics}

The study was approved by the Ruijin Hospital Ethics Committee (2018-98), and the subjects gave written informed consent. The study procedures, including the collection and analysis of patients' data, were in accordance with the Helsinki Declaration.

\section{Conflict of Interest Statement}

The authors have no conflicts of interest to declare.

\section{Funding Sources}

This study was supported by the National Key R\&D Program of China 2017YFA0104502 and National Natural Science Foundation Program 81770187.

\section{Author Contributions}

Z.-Y.W.., W.-H.G.", and H.-J.Z." collected and analyzed the data and helped to write the manuscript; C.-R.Y., Z.-W.W., L.W., and L.-N.W. helped to treat and follow-up the patients; L.T. and M.W. analyzed the data;R.D. helped to write the manuscript; and J.-M.W.*, P.-P.H.*, D.B.*, and J.H.* designed the study, supervised the study, and wrote the manuscript.

\section{References}

1 Mato AR, Morgans A, Luger SM. Novel strategies for relapsed and refractory acute myeloid leukemia. Curr Opin Hematol. 2008 Mar;15(2):108-14.

2 Thol F, Schlenk RF, Heuser M, Ganser A. How I treat refractory and early relapsed acute myeloid leukemia. Blood. 2015 Jul; 126(3):319-27.

3 Ferguson P, Hills RK, Grech A, Betteridge S, Kjeldsen L, Dennis M, et al. An operational definition of primary refractory acute myeloid leukemia allowing early identification of patients who may benefit from allogeneic stem cell transplantation. Haematologica. 2016;101(11):1351-8.

4 Ravandi F. Primary refractory acute myeloid leukaemia: in search of better definitions and therapies. Br J Haematol. 2011 Nov;155(4): 413-9.

5 Ravandi F, Cortes J, Faderl S, O’Brien S, Garcia-Manero G, Verstovsek S, et al. Characteristics and outcome of patients with acute myeloid leukemia refractory to 1 cycle of highdose cytarabine-based induction chemotherapy. Blood. 2010 Dec;116(26): 5818-6153.

6 Löwenberg B, Ossenkoppele GJ, van Putten W, Schouten HC, Graux C, Ferrant A, et al. High-dose daunorubicin in older patients with acute myeloid leukemia. N Engl J Med. 2009 Sep;361(13):1235-48.

7 Lee JH, Joo YD, Kim H, Bae SH, Kim MK, Zang DY, et al. A randomized trial comparing standard versus high-dose daunorubicin induction in patients with acute myeloid leukemia. Blood. 2011 Oct;118(14):383241.
8 Fernandez HF, Sun Z, Yao X, Litzow MR, Luger SM, Paietta EM, et al. Anthracycline dose intensification in acute myeloid leukemia. N Engl J Med. 2009 Sep;361(13):124959.

9 Trifilio SM, Rademaker AW, Newman D, Coyle K, Carlson-Leuer K, Mehta J, et al. Mitoxantrone and etoposide with or without intermediate dose cytarabine for the treatment of primary induction failure or relapsed acute myeloid leukemia. Leuk Res. 2012 Apr;36(4): 394-6.

10 Schlenk RF, Döhner K, Mack S, Stoppel M, Király F, Götze K, et al. Prospective evaluation of allogeneic hematopoietic stem-cell transplantation from matched related and matched unrelated donors in younger adults with high-risk acute myeloid leukemia: GermanAustrian trial AMLHD98A. J Clin Oncol. 2010 Oct;28(30):4642-8.

11 Willemze R, Suciu S, Meloni G, Labar B, Marie JP, Halkes CJ, et al. High-dose cytarabine in induction treatment improves the outcome of adult patients younger than age 46 years with acute myeloid leukemia: results of the EORTCGIMEMA AML-12 trial. J Clin Oncol. 2014 Jan;32(3):219-28.

12 Bergua JM, Montesinos P, Martinez-Cuadrón D, Fernández-Abellán P, Serrano J, Sayas MJ, et al. A prognostic model for survival after salvage treatment with FLAG-Ida +/- gemtuzumab-ozogamicine in adult patients with refractory/relapsed acute myeloid leukaemia. Br J Haematol. 2016 Sep;174(5):700-10.

13 Godwin CD, Gale RP, Walter RB. Gemtuzumab ozogamicin in acute myeloid leukemia. Leukemia. 2017 Sep;31(9):1855-68.
14 Schlenk RF, Fröhling S, Hartmann F, Fischer JT, Glasmacher A, del Valle F, et al. Phase III study of all-trans retinoic acid in previously untreated patients 61 years or older with acute myeloid leukemia. Leukemia. 2004 Nov; 18(11):1798-803.

15 Schlenk RF, Lübbert M, Benner A, Lamparter A, Krauter J, Herr W, et al. All-trans retinoic acid as adjunct to intensive treatment in younger adult patients with acute myeloid leukemia: results of the randomized AMLSG 07-04 study. Ann Hematol. 2016 Dec;95(12):1931-42.

16 Stone RM, Mandrekar SJ, Sanford BL, Laumann K, Geyer S, Bloomfield CD, et al. Midostaurin plus chemotherapy for acute myeloid leukemia with a FLT3 mutation. N Engl J Med. 2017 Aug;377(5):454-64.

17 Rashidi A, Weisdorf DJ, Bejanyan N. Treatment of relapsed/refractory acute myeloid leukaemia in adults. Br J Haematol. 2018 Apr; 181(1):27-37.

18 Schmid C, Schleuning M, Schwerdtfeger R, Hertenstein B, Mischak-Weissinger E, Bunjes $\mathrm{D}$, et al. Long-term survival in refractory acute myeloid leukemia after sequential treatment with chemotherapy and reduced-intensity conditioning for allogeneic stem cell transplantation. Blood. 2006 Aug;108(3):1092-9.

19 Decroocq J, Itzykson R, Vigouroux S, Michallet M, Yakoub-Agha I, Huynh A, et al. Similar outcome of allogeneic stem cell transplantation after myeloablative and sequentialconditioning regimen in patients with refractory or relapsed acute myeloid leukemia: a study from the Société Francophone de Greffe de Moelle et de Thérapie Cellulaire. Am J Hematol. 2018 Mar;93(3):416-23. 
20 Craddock C, Labopin M, Pillai S, Finke J, Bunjes D, Greinix H, et al. Factors predicting outcome after unrelated donor stem cell transplantation in primary refractory acute myeloid leukaemia. Leukemia. 2011 May; 25(5):808-13.

21 Michallet M, Thomas X, Vernant JP, Juentz M, Socie G, Esperou-Bourdeau H, et al. Longterm outcome after allogeneic hematopoietic stem cell transplantation for advanced stage acute myeloblastic leukemia: a retrospective study of 379 patients reported to the Societe Francaise de Greffe de Moelle (SFGM). Bone Marrow Transplant. 2000 Dec;269(11):115763.

22 Döhner H, Estey E, Grimwade D, Amadori S, Appelbaum FR, Büchner T, et al. Diagnosis and management of AML in adults: 2017 ELN recommendations from an international expert panel. Blood. 2017 Jan;129(4):424-47.

23 Creutzig U, Kaspers GJ. Revised recommendations of the International Working Group for diagnosis, standardization of response criteria, treatment outcomes, and reporting standards for therapeutic trials in acute myeloid leukemia. J Clin Oncol. 2004 Aug; 22(16):3432-3.

24 Fung HC, Stein A, Slovak M, O'donnell MR, Snyder DS, Cohen S, et al. A long-term follow-up report on allogeneic stem cell transplantation for patients with primary refractory acute myelogenous leukemia: impact of cytogenetic characteristics on transplantation outcome. Biol Blood Marrow Transplant. 2003 Dec;9(12):766-71.
25 Duval M, Klein JP, He W, Cahn JY, Cairo M, Camitta BM, et al. Hematopoietic stem-cell transplantation for acute leukemia in relapse or primary induction failure. J Clin Oncol. 2010 Aug;28(23):3730-8.

26 Anthias C, Dignan FL, Morilla R, Morilla A, Ethell ME, Potter MN, et al. Pre-transplant MRD predicts outcome following reducedintensity and myeloablative allogeneic hemopoietic SCT in AML. Bone Marrow Transplant. 2014 May;49(5):679-83.

27 Walter RB, Buckley SA, Pagel JM, Wood BL, Storer BE, Sandmaier BM, et al. Significance of minimal residual disease before myeloablative allogeneic hematopoietic cell transplantation for AML in first and second complete remission. Blood. 2013 Sep;122(10):1813-21.

28 Ogawa H, Ikegame K, Daimon T, Uchida N, Fukuda T, Kakihana K, et al. Impact of pretransplant leukemic blast\% in bone marrow and peripheral blood on transplantation outcomes of patients with acute myeloid leukemia undergoing allogeneic stem cell transplantation in non-CR. Bone Marrow Transplant. 2018 Apr;53(4):478-82.

29 Schlenk RF, Frech P, Weber D, Brossart P, Horst HA, Kraemer D, et al. Impact of pretreatment characteristics and salvage strategy on outcome in patients with relapsed acute myeloid leukemia. Leukemia. 2017 May; 31(5):1217-20.
30 Breems DA, Van Putten WL, Huijgens PC, Ossenkoppele GJ, Verhoef GE, Verdonck LF, et al. Prognostic index for adult patients with acute myeloid leukemia in first relapse. J Clin Oncol. 2005 Mar;23(9):1969-78.

31 Burnett AK, Goldstone A, Hills RK, Milligan D, Prentice A, Yin J, et al. Curability of patients with acute myeloid leukemia who did not undergo transplantation in first remission. J Clin Oncol. 2013 Apr;31(10):1293301.

32 Wattad M, Weber D, Döhner K, Krauter J, Gaidzik VI, Paschka P, et al. Impact of salvage regimens on response and overall survival in acute myeloid leukemia with induction failure. Leukemia. 2017 Jun;31(6):1306-13.

33 Wang L, Devillier R, Wan M, Decroocq J, Tian L, Fürst S, et al. Clinical outcome of FLAG-IDA chemotherapy sequential with Flu-Bu3 conditioning regimen in patients with refractory AML: a parallel study from Shanghai Institute of Hematology and Institut Paoli-Calmettes. Bone Marrow Transplantation. 2019 Mar;54(3):458-64.

34 Zhang WP, Yang D, Song XM, Ni X, Chen J, Chen L, et al. Allogeneic peripheral blood stem cell transplantation is a promising and safe choice for the treatment of refractory/relapsed acute myelogenous leukemia, even with a higher leukemia burden. Biol Blood Marrow Transplant. 2013 Apr;19(4):653-60. 